\title{
Digital TV Signal Reception Testing in a Device with Spatial Diversity
}

\author{
Eduardo Romani, Wyllian Bezerra da Silva, Marco Antônio Costa de Borba, Keiko Verônica Ono \\ Fonseca and Alexandre de Almeida Prado
}

\begin{abstract}
This paper presents the test results performed in internal and external environments employing tuner demodulator hardware with spatial diversity. Two types of antennae were used: monopole and hemispherical helical. The results demonstrated the superior performance of the system with spatial diversity.
\end{abstract}

Index Terms - Digital TV, Spatial diversity.

\section{INTRODUCTION}

$\mathrm{T}$ HE introduction of Digital TV transmissions in Brazil, in December 2007 has motivated this research, the development and testing of systems and equipment for the processing, transmission, and reception of video and audio signals [1] [2] [3] [4]. In particular, the development of reception systems has been the focus of many studies [5] [6]. The requirements for receiving LD signals (Low-Definition) and HD signals (High-Definition) in fixed and mobile environment can vary dramatically. The reception of HD signals is usually performed with an external directional antenna placed on the roof of a residence with an average height of 10 meters. If placed on a building whose height is variable, the signal will have to be distributed among the apartments with the use of a network of cables and amplifiers. However, there is a tendency to avoid external antenna and to make use of an internal antenna, generally coupled to an amplification system. On the other hand, LD signal reception in a mobile environment typically employs a smaller size and omnidirectional antenna with lower gain. It is also at a lower height from the ground, between 1 and 1.5 meters. In addition, the mobile signal is subject to fading and Doppler effects, making the received signal strength vary abruptly and with greater intensity fluctuation. The robustness of the modulation system (QPSK) used in LD signals compensates for these effects allowing its reception in adverse conditions. However, there is a tendency also to receive HD signals in the mobile environment. However, this would create new challenges for the reception of the signal. One solution to improve performance is to employ a system with spatial diversity reception, which can use two or more antennae. In this case, the signals from different antennae are evaluated and processed using specific algorithms to increase the carrier-tonoise ratio $(\mathrm{C} / \mathrm{N})$ at reception. A Project carried out between 2009 and 2010 by a group of universities (Inatel, Unicamp, Mackenzie, PUC-RS, UFSC, UTFPR), with participation of the Centro de Tecnologia de Informação (CTI), developed and tested a tuning demodulation system, using a market chipset [7]. The system developed allows reception with diversity through two antennae and uses a combination technique with a maximum ratio between the signals (Maximum Ratio Combining, MRC). This paper relates to the results of system tests performed on internal and external reception in Curitiba.

The paper is organized as follows: Section II describes the methodology for conducting the tests. Section III describes the results of tests considering reception with two different pairs of antennae used with the tuner demodulation system. Section IV contains the conclusion.

\section{Methodology}

The tuner demodulation system test was performed in internal and external environments with the use of two different pairs of antennae, namely, a pair of monopole antennae and a pair of hemispherical helical antennae (HHA), these antennae were developed by the Centro de Pesquisa em Tecnologia Wireless (CPTW) of the Pontifíca Universidade Católica de Rio Grande do Sul [8]. The design of the tunerdemodulator board was developed by the Laboratório de Desenvolvimento de Hardware do Inatel [9]. During the tests in Curitiba a RF spectrum analyzer (Agilent) and a TV signal analyzer (Rohde \& Schwarz) were used to check the signal level and certain features, such as echo pattern and the measurement locations.

The tests were carried out with the application of two different procedures: one for internal measurements, carried out inside the Universidade Tecnológica Federal do Paraná (UTFPR) and the others are field measurements, carried out in various parts of the city of Curitiba, both are detailed in the following sub-sections:

\section{A. Test Procedure for internal measurements}

In preparation for this procedure, the expected behavior of a home user when trying to receive a digital TV signal through an internal antenna was used as the criteria, in this case, the pair of antennae has been kept close to the tuner, but the antennae were separated by a half wavelength (in the case of monopole antennae). The assembly was placed in the environment to maximize the received signal level at the input of the spectrum analyzer.

The test configuration is seen in Fig. 1. The pair of antennae (monopole or HPA) is connected to the tuner input. An ASI connection (Asynchronous Serial Interface) has been developed especially on the tuner card to allow the signal 
output to go to a Dektec (STP-225), which allows analysis of transport stream (TS) of the received signal. In turn, an output of the DTU is connected to a laptop, which can access the analytics platform provided by the DTU and collect data that is recorded in a log file, in an automated manner. These values are recorded in a cvs file and subsequently transferred to a spreadsheet for analysis and processing. The ASI connection between the tuner and the DTU also allows the recording of TS, thanks to StreamXpert software.

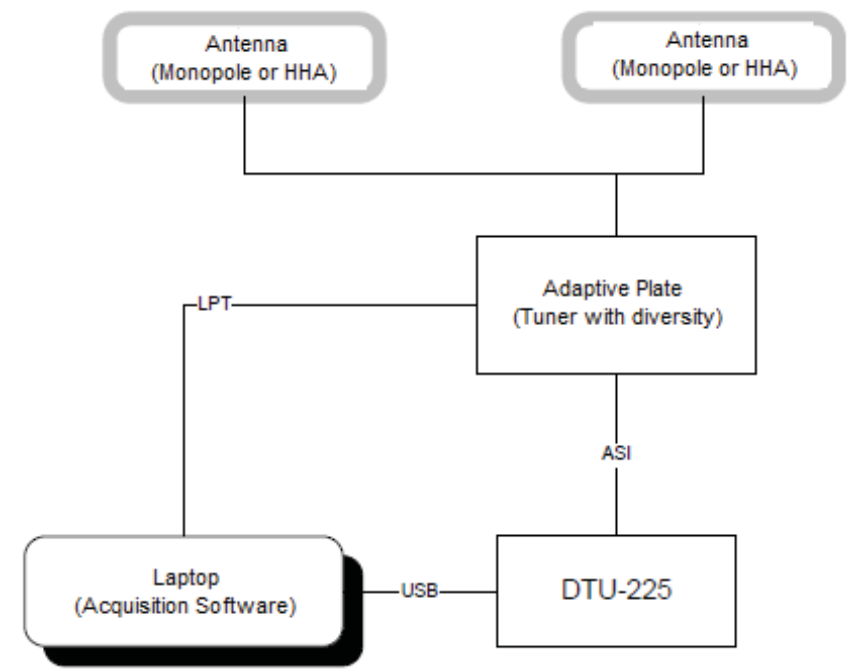

Fig. 1. Assembly diagram of equipment for internal measurements

Due to the extreme variability of the signals in the indoor environment, the following antenna alignment procedure was adopted and repeated in each of the locations measured:

- With a monopole antenna (less directional) in an upright position, connected to the spectrum analyzer input (programmed to indicate the total power received in the channel with $6 \mathrm{MHz}$ bandwidth), seeks the position that provides the maximum received power. Thus, defines the position of the antenna called Av; recording the received power value of the spectrum analyzer, determined by the function averaging 100 scans. The averaging time is 10 seconds.

- Repeating the same procedure with the second monopole antenna coupled to the analyzer input; in a vertical position, the position being defined the Bv antenna;

- The previous two steps are repeated, with the monopole antenna in horizontal position, determining the positions Ah and $\mathrm{Bh}$;

- A procedure analogous to the maximization of the received signal is adopted with the two HHA antennae. As both are mounted on the same vertical mast, after finding the optimal position for the upper antenna, the lower antenna turns itself until it points in the direction of maximum reception, following a reading taken by the spectrum analyzer. Registering the azimuth at each location, and the received power value of the spectrum analyzer, smoothed by the averaging function in 100 scans. The azimuth recorded is the angle between the directions of maximum antenna gain relative to the perpendicular direction to the north wall of the room, measured clockwise for those who look up at the antenna.

- After the maximization of the power points being carried out at the chosen location, the analyzer antenna is disconnected and, the tuner system connected. Tune to the chosen channel through the software that comes with the tuner that runs on the Linux operating system, and emulated by VMWare Player. If the signal can be accessed by the decoder, the DCT-320 StreamXpert software is used for accessing the signals in LD (Low Definition) and HD (High Definition) resolution.

- If the signal can be accessed at the measurement point, the TS and data logs received by tuner are recorded, such as AGC (Automatic Gain Control), SNR (Signal-to-Noise Ratio), BER (Bit Error Rate), and MER (Modulation Error Rate). This data is recorded individually in files for the master modes (main tuner), slave (secondary) and combined mode.

\section{B. Test Procedure for external measurements}

To perform the external measurements apply the same procedure for aligning the antenna for internal measurements as described, however for the external measurements are taken at several locations in Curitiba, setting up the equipment and positioning the antennae with the aid of the test vehicle on loan from Rede Paranaense Comunição (RPC). Measurements were performed with the vehicle stationary and with the aid of a Rhode Schwartz spectrum analyzer [10], whose output was coupled to a laptop through an Ethernet connection. The laptop has software developed by UTFPR, which performs the collection and storage of received data. The plotting of the data is graphically performed overlaying it on a map via a Google Maps API (Application Programming Interface). The geographical position of each measured location is obtained using a GPS unit that is connected to the same laptop through a USB connection, as seen in Fig. 2.

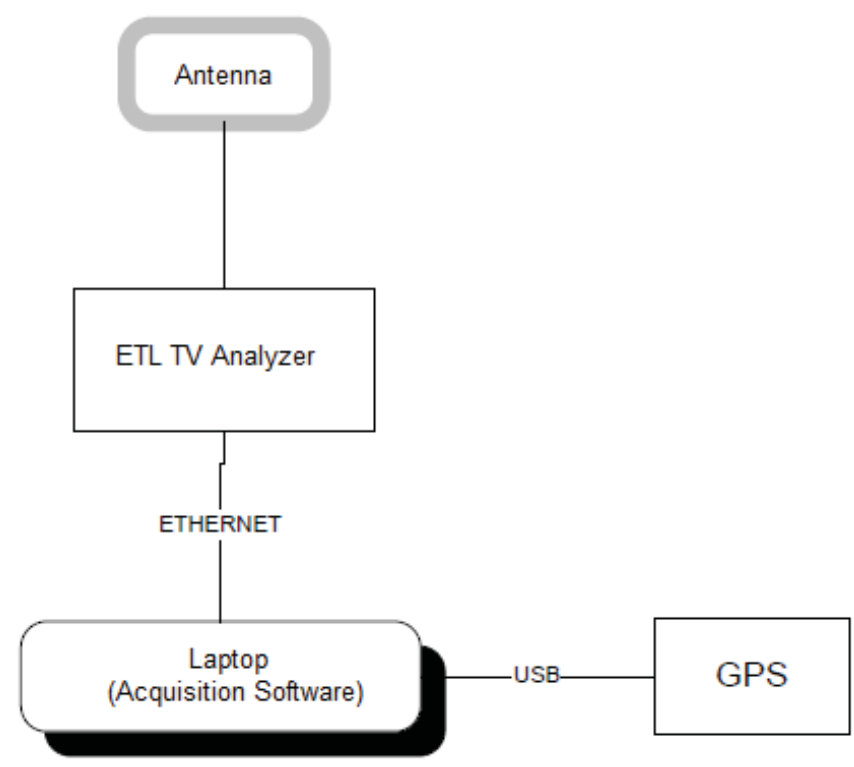

Fig. 2. Field trial system diagram

\section{RESULTS}

In the following sub-sections, the results are described, 
using the above procedures.

\section{A. Internal measurement results}

Indoors measurements were completed at 13 locations inside the UTFPR buildings, located in the center of Curitiba, at an approximate distance of $3.3 \mathrm{~km}$ from the transmitting antenna (channel 41). Fig. 3 shows a plan of the buildings in which the measurements were performed, noting that eight of them were taken on the ground floor, four on the first floor, and one in the basement.

Fig. 4 shows a graph of the received power at the input of the spectrum analyzer in the search function at the measurement location. The locations plotted on the horizontal axis begin with the basement location, continuing based on the height of the measurement location. From the results, it is evident that the HHA antenna provides better reception quality than the monopole antenna. The comparison shows that in only two locations did the monopole exceeded the performance of the HHA antenna, but in only one of these locations was it possible to access the signal. The HD signal could be accessed in 4 of the 13 locations with the HPA antenna while it could only be accessed in only 1 location with the monopole antenna. Note that the signal threshold to display the video is $-74 \mathrm{dBm}$.

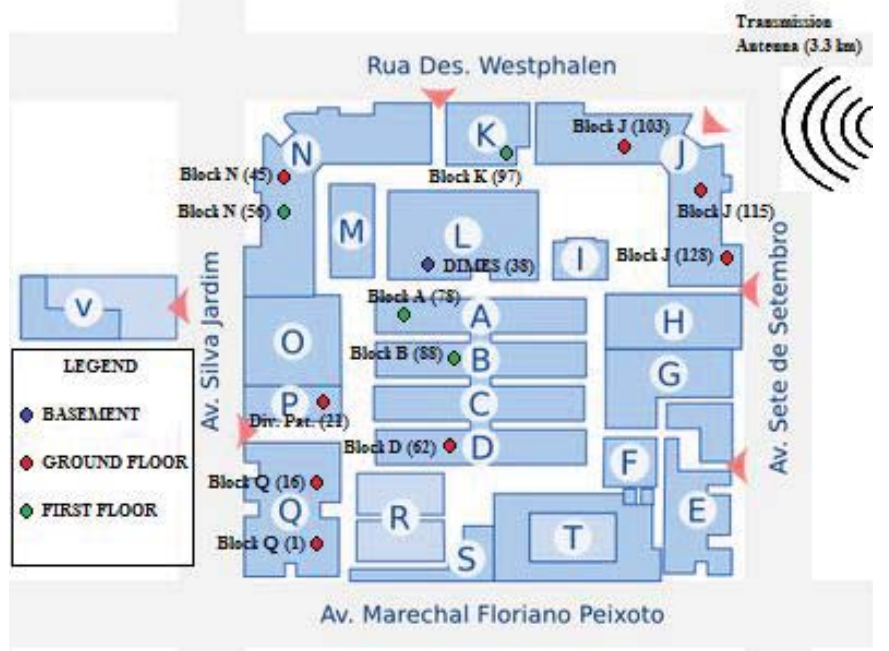

Fig. 3. SNR in each of the 202 samples in $\log 128$.

Specifically, a comparison between the measurements can be stated as:

- In 5 of the 13 sites it continues to not be possible achieve reception of the signal, even with the use of spatial diversity and the use of more directive antennae;

- In locations closer to an opening (door, window, etc.) directive antennae performed better than the monopole antennae, and its optimal direction was related to the opening position: either pointing directly at it or a wall or object that more effectively reflects the signal that had passed through the opening;

- Where it was not possible to access and display video, the signal level was very close to or below the sensitivity threshold of the tuner $(-77 \mathrm{dBm})$.

- As the measurements were carried out during normal university hours, people were moving in the vicinity of the antennae. At least one of the sites $(\log 21$, Block P) this influence, was perceived; there was some variation in received power $\mathrm{dB}$ by the spectrum analyzer. However, no effect on the image was noticed.

As an example, Fig. 5 shows the signal-to-noise ratio (SNR) measured at Block J - Ground floor (log 128) with the tuner. The curves show the behavior of the SNR at each input (master and slave) and the combined SNR of the two antennae. It appears that the combined SNR is a few $\mathrm{dB}$ greater than the SNR of the individual antennae. In particular, it is observed that the combined value is valid until sample 140 , and after this there is a loss of signal reception in the master antenna (probably due to the existence of a disconnection), causing the combined SNR value to agrees with the SNR value originating from the slave antenna.

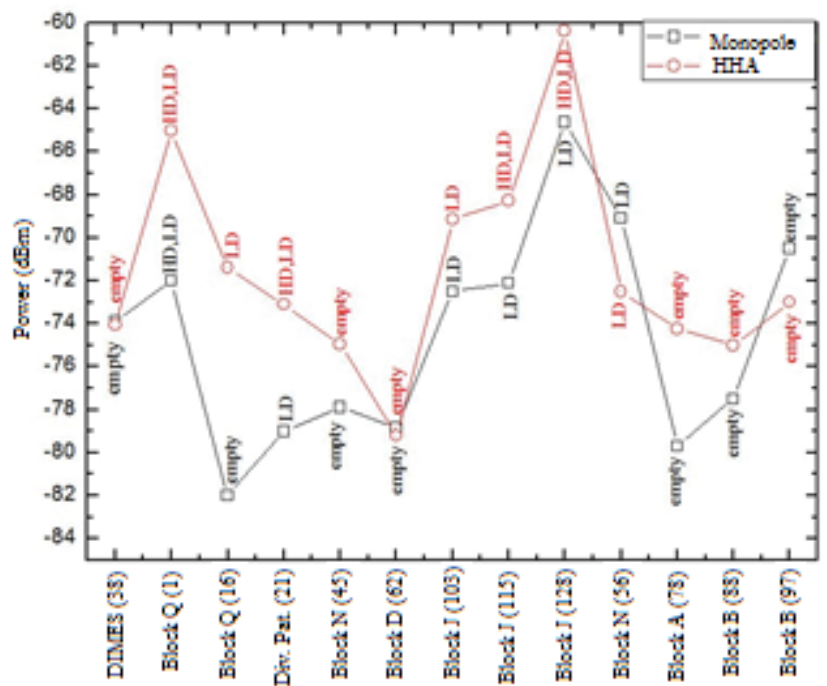

Fig. 4. Power measurements $(\mathrm{dBm})$ in the indoor environment with an indication of accessing $\mathrm{LD}$ and $\mathrm{HD}$ signals

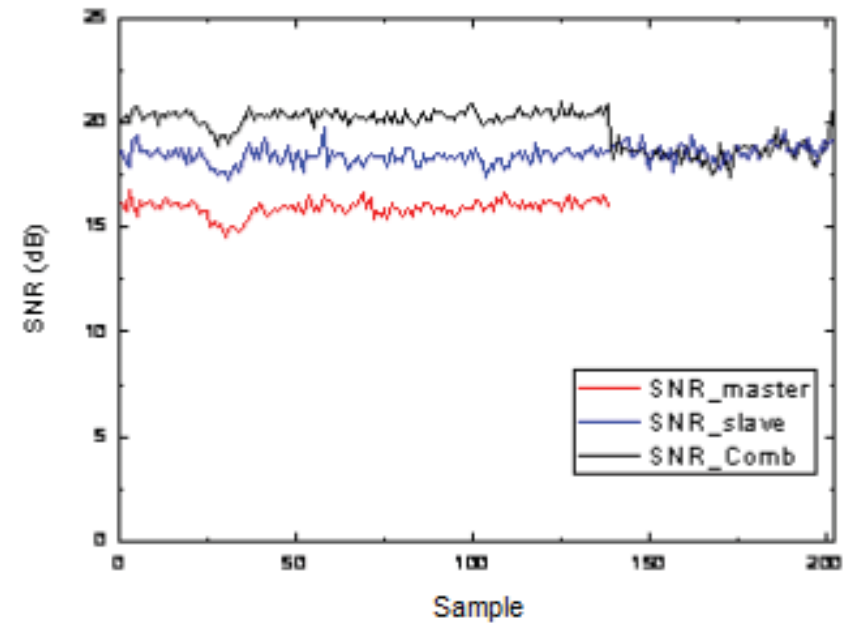

Fig. 5. SNR in each of the 202 samples of $\log 128$

\section{B. External measurement results}

Nine (9) locations in the region of Curitiba were chosen to carry out the external measurements; these points had already been at locations with reception difficulty during when 
measurements were conducted in 2008 [3]. The purpose was to verify the performance of the tuner with spatial diversity at these locations. Initially, the signal characterization at the sites was performed with an ETL analyzer.

Table I provides information on the distances between the locations and the transmitting antenna, as well as the received power in the spectrum analyzer with each of the antennae.

TABLE I

DESCRIPTION OF THE LOCATIONS AND SIGNAL POWER AT RECEPTION

\begin{tabular}{ccccc}
\hline \hline Location & $\begin{array}{c}\text { Distance to } \\
\text { the Antenna } \\
(\mathrm{km})\end{array}$ & Altitude $(\mathrm{m})$ & HHA & Monopole \\
\hline 16 & 0.71 & 915.2 & -29.75 & -32.2 \\
\hline 34 & 1.05 & 928.3 & -46.79 & -39.72 \\
\hline 38 & 2.09 & 942.6 & -47.53 & -43.25 \\
\hline 53 & 4.07 & 908.5 & -51.45 & -51.16 \\
\hline 55 & 3.99 & 898 & -50.72 & -64.3 \\
\hline 56 & 3.94 & 895.4 & -61.92 & -72.87 \\
\hline 75 & 5.92 & 919.3 & -64.05 & -73.58 \\
\hline 79 & 6 & 949.1 & -59.87 & -68.63 \\
\hline 93 & 9 & 901.1 & -80.05 & -86.05 \\
\hline 94 & 8.04 & 931 & -53.63 & -62.94 \\
\hline \hline
\end{tabular}

The distribution of the nine sites can be seen in Fig. 6, this also shows the measured power of the signals received by the HHA antenna using the TV analyzer. Note that at one location (93) the level was below the $-70 \mathrm{dBm}$ threshold established in the software. (However, it notes that the tuner sensitivity was observed at around $-77 \mathrm{dBm}$ ).

The use of the ETL analyzer allows other parameters to be measured, such as the MER and the echo patterns related to multipath problems.

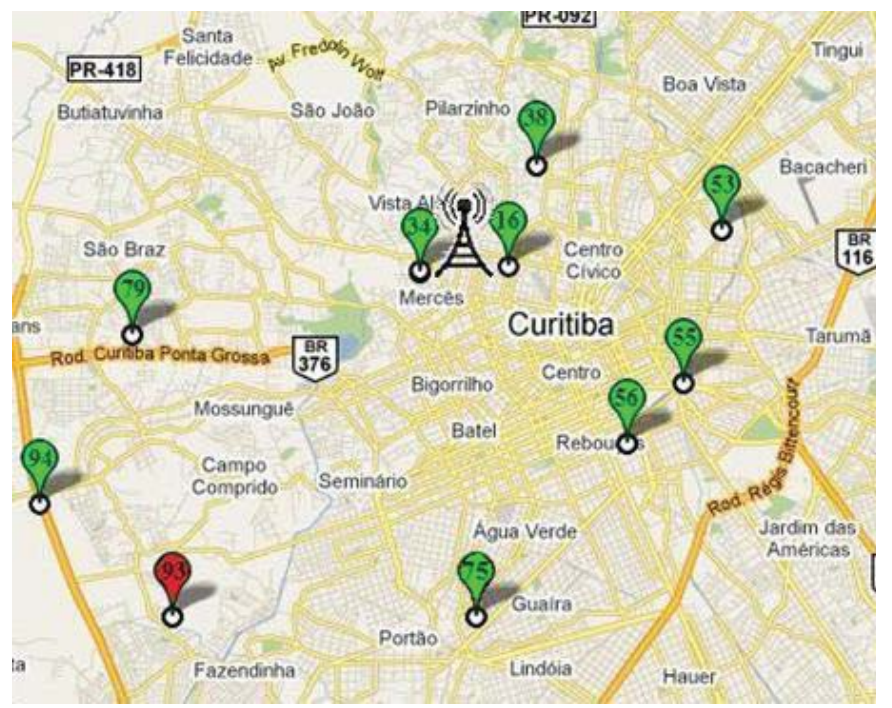

Fig. 6. Signals picked up with a HHA by an ETL TV Analyzer

The behavior of the received power as a function of the distance from the transmitting antenna can be seen in Fig. 8. Note the progressive decay of the largest signal level as the distance increases from the transmitting antenna. This decay theoretically occurs in an inversely proportional manner to the distance from the transmitting antenna, but in the chart it can be observed that some locations further away from the antenna have a greater signal amplitude than some closer locations, this occurs due to medium interference, such as buildings, vehicle movement near the measurement location, and also by multipath signals. In Fig. 7 the best performance of the HHA antenna in relation to the monopole antenna can be seen.

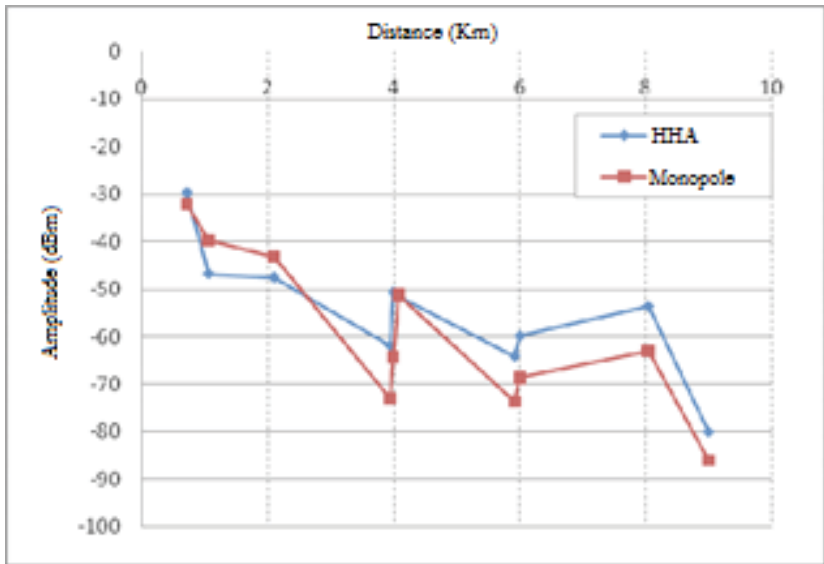

Fig. 7. Signal amplitude measurements $(\mathrm{dBm})$ versus distance $(\mathrm{km})$ in the external environment

The ETL analyzer allows the recording of standard echo signals at the measurement location, enabling the characterization of the multipath, that is, channel signals arriving at the receiving antenna along different paths. Figs. 8 and 9 show the relative echo amplitude $(\mathrm{dB})$ versus time. The measurement is performed by taking the maximum received value as a reference for time $t=0$. Negative values on the time axis represent lower amplitude signals that arrived at the analyzer first in relation to the highest measured signal amplitude. It can be seen that the amplitude of the echoes decreases the greater the delay time. It is observed that the maximum verified time delay in both cases, with reduced amplitude of $40 \mathrm{~dB}$ is relation to the maximum value, is less than the guard interval of the transmitted signal, which is 64 $\mu \mathrm{s}$.

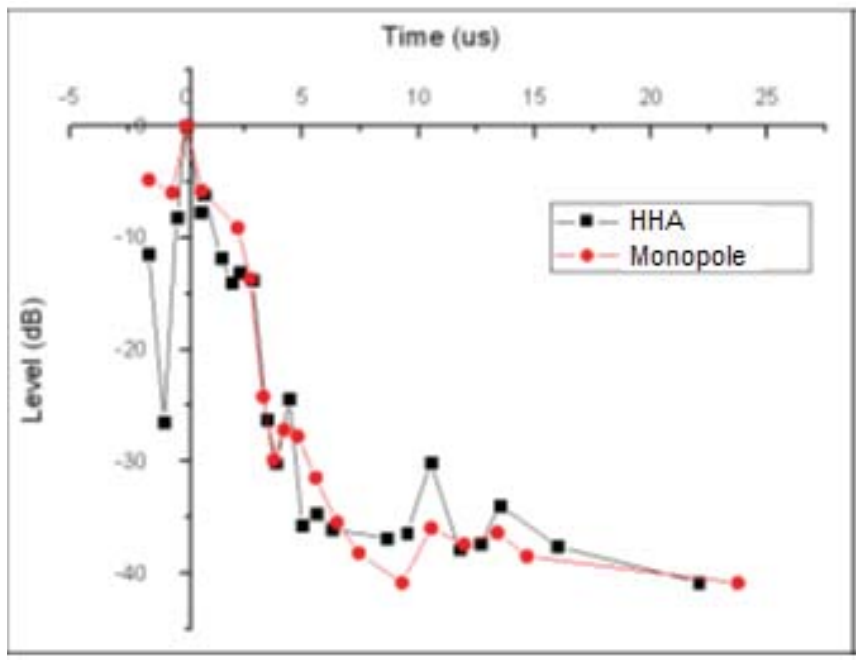

Fig. 8. Multipath signal measurements at location 79 


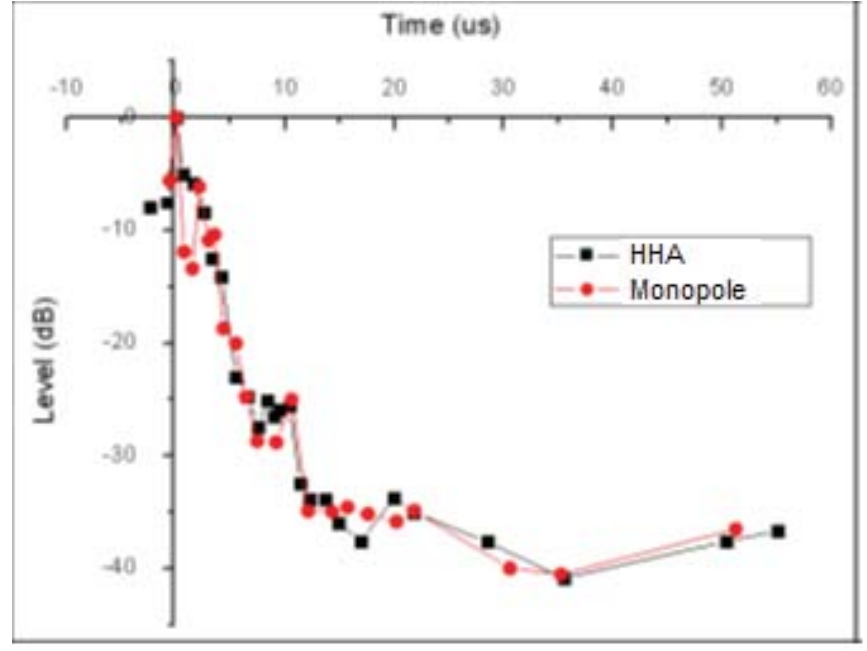

Fig. 9. Multipath signal measurements at location 94

The tuner-demodulator system was employed to make measurements at selected points, using, in this case, the HPA antennae. As noted in the internal measurements, the result of combining the master and slave signals produces a greater SNR value. This gain can reach a few dB, as shown in Fig. 10.

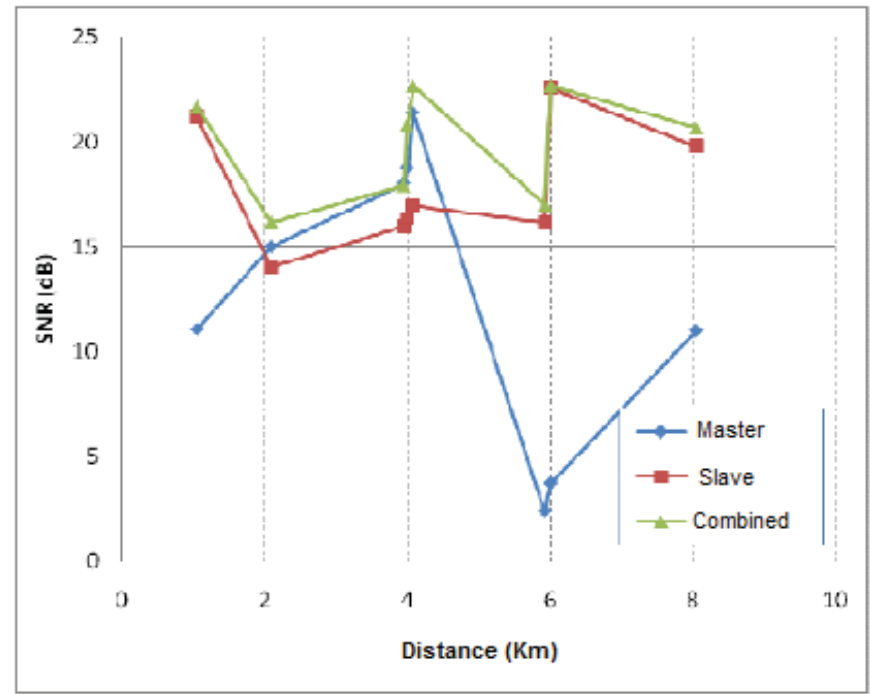

Fig. 10. SNR measurements $(\mathrm{dB})$ versus distance $(\mathrm{km})$ in the external environment

Another advantage of the system with spatial diversity is related to the fact that it provides the same SNR value, even when the signal at one of the antennae suffers a marked drop. In this case, the receiver will receive the antenna signal with the highest SNR. This situation is exemplified in the three most distant locations in Fig. 10, where the master antenna showed a sudden drop in SNR, while the slave input signal remained at acceptable levels, making the combined SNR acceptable.

\section{CONCLUSION}

Field measurements were performed with HPA and monopole antennae using tuning modulation hardware with spatial diversity.

The measurement sites chosen were those previously selected for measurement in 2008, for both the UTFPR campus locations and the external locations.

The placement method chosen for the antennae tried to approximate the behavior of a home user seeking to receive TV signals with an internal antenna, who would try to achieve the positioning that provides the best reception.

In most places, the reception performance with the HHA antennae exceeded that observed with the monopole antennae.

It was difficult to obtain HD signals with power below -71 $\mathrm{dBm}$ while collecting the external measurements data. In addition, the reception of the high definition signal was subjected to variations in the master and slave channels, as well as disturbances at the measurement site. However, the use of spatial diversity provided a gain in the SNR of the combined signal of 2-3 dB when compared to those observed in the individual channels (master and slave).

Due to hardware difficulties of the HHA antennae on top of the test vehicle in Curitiba, signal capture could not be performed with the vehicle moving. Thus, the system performance faced a critical problem, the influence of the Doppler Effect and multipath could not be evaluated.

\section{ACKNOWLEDGMENT}

The authors acknowledge the research group at Laboratório de Desenvolvimento de Hardware do Inatel, coordinated by Prof. Luciano L. Mendes, responsible for the development of the tuner-demodulator board. The Centro de Pesquisas em Tecnologias Wireless, coordinated by Prof. Fernando César Comparsi de Castro, responsible for developing the HHA antenna and the Grupo Paranaense de Comunicação, in particular Mr. Ivan Miranda, for making the vehicle available for carrying out the tests in the external environment.

\section{REFERENCES}

[1] G. Bedicks et al., "Results of the ISDB-T system tests, as part of digital TV study carries out in Brazil," IEEE Trans. Broadcasting, vol. 52, no. 1, pp. $38-44,2006$.

[2] B. P. Constanzo, and J. A. Neto, "Analysis of the Brazilian Digital TV System and Signal-Converting Devices," in PICMET, 6-9 August, Portland, 2007 pp. 1830-1838.

[3] C. L. Vasco et al, "Ensaios de Transmissão e Recepção de TV Digital Terrestre na Região Metropolitana de Curitiba," Revista de Radiodifusão, vol. 3, no. 3, pp. 63-76, 2009.

[4] W.B. da Silva e A. A. P. Pohl, "Framework de baixo custo para ensaios de TV digital", in XXIX Simpósio Brasileiro de Telecomunicações, Curitiba, 2-5 October, 2011.

[5] R. E. Motoyama, F. Yamada, C. Akamine e G. M. Valeira, "Método de Avaliação da Recepção do Sistema ISDB-Tb em Ambiente Indoor," Revista de Radiodifusão, vol. 3, no. 3, pp. 206-211, 2009.

[6] C. Akamine et al., "Field Trial for Brazilian DTV Using Space Diversity", in IEEE International Symposium on Broadband Multimedia, BMSB 2010, , Shangai, China, 24-26 March, 2010, pp. 1-11.

[7] Projeto SIRDAI, "Sistema de Recepção com Diversidade e Antenas Inteligentes para TVD desenvolvido no âmbito do Centro de Tecnologia de Informação e Comunicação (CTIC/MCT), gerenciado pela Rede Nacional de Pesquisas (RNP)

[8] http://www.pucrs.br/cptw/ 
SET INTERNATIONAL JOURNAL OF BROADCAST ENGINEERING - SET IJBE v. 1, Article 9, 6p.

[9] http://www.inatel.br/

[10], R\&S ETL TV Analyzer.

Romani, E., Bezerra da Silva, W., Costa de Borba, M. A., Ono

Fonseca, K. V. and de Almeida Prado, A.; 2015. Digital TV Signal

Reception Testing in a Device with Spatial Diversity. ISSN Print:

2446-9246 ISSN Online: 2446-9432. doi: 10.18580/setijbe.2015.9

Web Link: http://dx.doi.org/10.18580/setijbe.2015.9 